\title{
The Interpretive Shaping of Music Performance Research
}

\author{
JOHN RINK \\ AHRC Research Centre for Musical Performance as Creative Practice \\ University of Cambridge
}

\begin{abstract}
In their study of nine pianists Buck, MacRitchie and Bailey observe a universal embodiment of phrasing structure and other higher-level structural features of the music, the physical makeup of which is nevertheless particular to both the individual performers and the pieces they are performing. Such a conclusion invites renewed consideration of assumptions in the literature on musical performance about the nature and role of structure and about performers' 'interpretations' thereof. The findings also raise interesting questions about the musical viability of empirical research on performance and its capacity to shed light on how performers shape the music they play, their motivations in doing so, and how those listening to them might in turn be affected by this.
\end{abstract}

Submitted 2013 June 9; accepted 2013 June 11.

KEYWORDS: performance, musical structure, shape, motion, gesture, phrasing

\section{CONTEXTS, PREMISES, AIMS}

ALTHOUGH the research undertaken by Buck, MacRitchie and Bailey is enterprising, innovative and potentially significant, I have some reservations about their methodology and the emergent results, which in turn relate to a healthy scepticism about aspects of empirical work on musical performance more generally. I must stress, however, that my reaction on the study in question is fundamentally positive, as the comments below should make clear.

I have long argued that the intractable, inscrutable nature of musical performances typically requires the application of complementary approaches and perspectives.[1] To that end the mixed-methods design of this study is salutary. By using three-dimensional motion capture, visual and auditory recordings, and post-performance interviews with performers referring to marked-up scores, the authors test two main hypotheses, namely that the nature and form of the motion patterns traced through what they term 'nontechnical, concurrent performance motions' may be 'related to each performer's intended expression of structural hierarchy as they interpret it within the compositions', and that these 'structural performance gestures may be highly individualized and potentially dependent on a performer's personalized style and interpretation'.

When I encountered this work at the conference on Music and Shape at King's College London in July 2012, I was so impressed that I asked the presenters (MacRitchie and Buck) whether I could show several of their slides in my keynote paper at ICMPC-ESCOM in Thessaloniki a few weeks later, in a survey of performance-analytical work on a case-study piece, Chopin's B minor Prelude Op. 28 No. 6.[2] I wonder whether my reaction might have been different had I just read the article: not only were the conclusions in the presentation tighter in focus and articulation, but the live version was much more immediate - just as the experiencing of music in sound and time potentially has so much more power of persuasion than reading a notated score of that music. The impressive spherical analyses also came to life when shown on a screen, as against their static counterparts on the page.

This distinction between 'notated' and 'live' underlies some of the reservations mentioned above. One of the fundamental premises of the authors' research is an understanding of musical structure that has more to do with music as notation than with music as process. I am by no means the only advocate at present of a fundamental reconceptualisation of musical structure, one that takes into account the creative role of performers in giving music shape or, to put it another way, in inferring structural relationships from musical materials and then enacting them as they see fit within the broader musical narrative of their performance. This proposition is quite different from the conventional view that music 'has' structure (note the singular) and that the task of performers is to reproduce it in their performances. On the contrary: whatever representations of structure may be developed by individual performers, their 'projections' thereof 
will be influenced by an enormous range of factors of which such attributes as phrase structure are only part. Thus, singling out phrase structure, as is done here, runs the risk of producing musically skewed results however valid those results may be in respect of defined parameters.

Other premises of the study are that performers physically 'accommodate' musical materials in their playing; that non-technical motions can display expressive and structural qualities which will influence 'audience interpretations'; that 'before performance gestures may be successfully and consistently computationally detected, they must first be identified over multiple instances, performers and performances as being repeatedly produced and conceptually meaningful'; and that phrase structure in particular is embodied through non-technical motions, a conclusion reached by the authors in their previous research. Further investigation of the last issue is the study's main aim, with a view to finding quantifiable links between given motion patterns and 'intended or notated structural and emotive expressions of meaning across multiple music performances'. I will address all of these points in the remarks that follow.

\section{THE PRELUDE REVISITED}

The authors note that the phrase structure in Chopin's Prelude in B minor - the focus of their investigation - is ambiguous, particularly compared with that of the Prelude in A major Op. 28 No. 7, which featured in their prior research and here is used referentially. They mark up a score from the Mutopia project (reproduced in an appendix to the article) to show 'phrasing boundaries as taken from theoretical analyses', though without specifying which analyses they mean. In fact, the ambiguities are even more extensive than they suggest. According to Cone (1968, p. 80), 'The composer who really absorbed, digested, assimilated, and nourished himself on the four-measure concept was Chopin. ... [T] he norm became so nearly instinctive that he could temper it with cross-rhythms and syncopations in the large'. This is one of those cases, especially in 'phrase 5', which can be parsed in different ways, in addition to which an implied hemiola in bar 13 further interrupts the regularity of the metrical pulse. Bar 18 is also ambiguous as a result of dove-tailing, while bar 22 could be seen as either the fourth and last bar in a standard four-bar group or, conceivably, as a 'downbeat' in a four-bar hypermeasure extending into the last bar in the piece.

Buck, MacRitchie and Bailey are of course not expected to present a thoroughgoing analysis of the work, but further recognition of the degree of ambiguity therein might have supported their arguments about performer individuality versus global embodiment. In other words, given this degree of ambiguity, it would have been untenable to expect consistency across performers in their articulation of the phrasing, whether through physical means or others. What they certainly should have done, however, is use a much better score, as the Mutopia edition is lamentably poor. Not only would Chopin turn in his grave at the epigraph 'Tolling Bells',[3] but inauthentic editorial interventions abound.[4] Concerns about such matters should not be dismissed as pedantic: even the most minute notational details have the potential to shape a performer's understanding of the music, and in this case the imposed pedallings, dynamics, etc. directly relate to phrase structure. On the one hand, the use of a readily downloadable if inferior score achieves a sort of perverse ecological validity, as musicians often succumb to the temptation to play from whatever score they can find. On the other, it is regrettable, given the sensitivity that the authors display in analysing the gathered data, that the musical viability of their results may have been compromised by using a score which possibly distorted the nine pianists' representations of phrase structure.

\section{AT THE KEYBOARD}

From the standpoint of ecological validity the use of an electronic keyboard rather than an acoustic piano is also problematic. Moreover, the fact that the nine participants were 'applauded into the recording room ... so as to maintain the feeling of a live performance setting' does not mean that such a feeling was gained and it is hard to judge the likelihood of this as we are not told how many spectators were present nor the nature of the performance space. In view of the authors' laudable commitment to studying gestures against the backdrop of 'multiple instances, performers and performances', it seems odd that each of the three pieces appears to have been played only once by the individual pianists. The conclusions that emerge might have been reinforced or indeed challenged had multiple performances of each work been elicited. I infer from the final sentence in the article that this is now the authors' intention.

I am ultimately not persuaded that the proposed links between non-technical motions and both phrase structure and 'higher-order structure' more generally are musically meaningful, at least not for the reasons given. I suspect that they are more coincidental than causal, reflecting musicians' unique physical dispositions and musical prerogatives. 
We need to remember that phrases are largely defined by cadences that punctuate the musical flow. Cadences typically involve a combination of melodic, harmonic and rhythmic properties; they range from weak to strong, depending not only on these various properties but also on context. By definition, cadential material differs from non-cadential material, which means that the technical motions required to play that material will differ - whether minutely or substantially - from those pertaining to non-cadential material. Because of possible sympathetic association between technical and non-technical motions arising from a musician's distinct physical makeup and gestural 'personality', there is every likelihood that non-technical motions at cadence points, which is to say phrase boundaries, will themselves differ in some way from a performer's non-technical motions at other points in the music, without those motions being directly governed or even triggered by higher-order structural considerations as such.

Similarly, the music's expressive properties as conceived by individual performers may invite or result in a range of non-technical motions without the latter necessarily having any immediate relation to the structural status of the given passage. A good example of this can be found in bars 13-14, which the authors (misleadingly) describe as both a C major 'modulation' and the Prelude's harmonic climax. Here we reach a new registral extreme in the left hand, the sonorous potential of which is augmented by the successive pedal indications (the first to occur in Chopin's manuscript); furthermore, for the first time in the piece the ascending left-hand arpeggiation is repeated, in contrast to the symmetrical melodic contours elsewhere. Interestingly, Chopin apparently conceived the two ascending arpeggiations at contrasting dynamic levels, judging from the respective ' $f$ ' and ' $p$ ' that he pencilled into the score of one pupil (with similar autograph annotations added to those of others). The two-bar passage ends with a unique moment of silence in the left hand as the right hand briefly takes over the melody. All of this is to say that the two bars in question are strikingly anomalous, including the implied hemiola and phrasing ambiguities referred to earlier. It is partly because of these very properties that the passage ends up having a pivotal (though not really 'climactic') role in the Prelude. Nevertheless, the fact that the music here may be distinctively shaped by pianists is not because of that pivotal role as such, as if a musician says to him- or herself, 'The passage here is a turning point: I had better convey that to my listeners through my non-technical motions.' Instead, the music's multifarious properties will be weighed up both individually and in the context of the broader musical narrative, possibly taking on a pivotal role within the performance not because this is dictated by either the composer or the score but because the given pianist has decided that this is how the properties should function locally and globally.

Thus we arrive at the conclusion that the perceived relationships between musical materials may engender responses on the part of the performer - whether physical and otherwise - which in turn may be construed by listeners as structurally significant within a particular performance. This turns the usual formulation on its head: rather than musical structure prescribing what performers do, we find that what performers do has the potential to impart meaning and create structural understanding.

\section{AFTER THE FACT(S)}

For obvious reasons Buck, MacRitchie and Bailey did not include transcripts of the post-performance interviews with the nine pianists nor the marked-up scores that the latter were asked to produce. It would nevertheless have been interesting to see these to determine whether the various verbal and analytical reflections were influenced by the authors' focus on structural considerations as discussed above.

Be that as it may, it must be recognized that speaking and writing about music in general and about why one plays it in such and such a manner is extremely difficult. This has partly to do with the inscrutability that I mentioned earlier, as we lack the means to explain complex actions and reactions quite apart from the problem that overt disclosure of musicians' self-reflections is too rarely sought. In that sense the approach taken here is welcome, as the nine pianists were not only observed in the heat of action but also listened to afterwards. Fostering disclosure of this kind is of critical importance if music performance research is to realize its full potential, and if the 'facts' that emerge through designated procedures and processes are to shed meaningful light on music and on the ways in which performers enact it. All of the information that emerges then requires interpretation, which (ironically) may be a more essential part of the research process than it is widely assumed to be of the practice of performance.

Although my comments throughout this review indicate that a broader range of musical factors might profitably have been considered by Buck, MacRitchie and Bailey, I maintain that within their defined parameters the authors have taken a commendable step towards enhancing our awareness of what performers do - both technically and non-technically - and in raising new questions that they and indeed the rest of us will now seek to answer. 


\section{NOTES}

[1] By way of example, such breadth was the basic premise of Rink (1995), as explained in the Preface (pp. ix-xiii).

[2] I had chosen this Prelude partly because of its prevalence in recent research, e.g., Dodson (2011a, 2011b), Ohriner (2012) and Küssner (2013).

[3] In a letter from 1841 Chopin railed against the 'stupid titles' supplied against his wishes by the London publisher, Wessel.

[4] These include:

- added expression marks (molto cantato, simile, espressivo)

- added or altered dynamic indications ( $p$ in bar 1; $p p$ in bar 22; $p p p$ rather than Chopin's $p p$ in bar 25 ; truncated crescendo/decrescendo hairpins; added decrescendos in bars 6 and 10)

- additional pedallings (una corda in bars 1 and 22, and tre corde in bar 15, whereas in the primary sources pedal markings occur only in bars 13 and 23)

- a change of pedal then a pedal release at bar 24, versus Chopin's single 'open pedal' from bar 23 to the double barline at the end

- broken slurring at bar 20, to conform to bar 16.

\section{REFERENCES}

Cone, E.T. (1968). Musical Form and Musical Performance. New York: Norton.

Dodson, A. (2011a). Expressive asynchrony in a recording of Chopin's Prelude No. 6 in B Minor by Vladimir de Pachmann. Music Theory Spectrum, Vol. 33, No. 1, pp. 59-64.

Dodson, A. (2011b). Expressive timing in expanded phrases: an empirical study of recordings of three Chopin preludes. Music Performance Research, Vol. 4, pp. 2-29.

http://mpr-online.net/Issues/Volume\%204\%20[2011]/Dodson.pdf

Küssner, M.B. (2013). Music and shape. Literary and Linguistic Computing. Vol. 28, No.3, pp. 472-479.

Ohriner, M.S. (2012). Grouping hierarchy and trajectories of pacing in performances of Chopin's Mazurkas. Music Theory Online, Vol. 18, No. 1.

http://mtosmt.org/issues/mto.12.18.1/mto.12.18.1.ohriner.php

Rink, J. (Ed.) (1995). The Practice of Performance: Studies in Musical Interpretation. Cambridge: Cambridge University Press. 